Article

\title{
First Trimester Microelements and Their Relationships with Pregnancy Outcomes and Complications
}

\author{
Małgorzata Lewandowska ${ }^{1,2, * \mathbb{D}}$, Barbara Więckowska ${ }^{3}$, Stefan Sajdak ${ }^{2}$ and Jan Lubiński ${ }^{4}$ \\ 1 Medical Faculty, Lazarski University, 02-662 Warsaw, Poland \\ 2 Division of Gynecological Surgery, University Hospital, 33 Polna Str., 60-535 Poznan, Poland; \\ ssajdak@ump.edu.pl \\ 3 Department of Computer Science and Statistics, Poznan University of Medical Sciences, \\ 60-806 Poznan, Poland; barbara.wieckowska@ump.edu.pl \\ 4 Department of Genetics and Pathology, International Hereditary Cancer Center, \\ Pomeranian Medical University, 71-252 Szczecin, Poland; lubinski@pum.edu.pl \\ * Correspondence: mal2015lewandowska@gmail.com
}

Received: 28 March 2020; Accepted: 13 April 2020; Published: 16 April 2020

\begin{abstract}
Microelements involved in the oxidative balance have a significant impact on human health, but their role in pregnancy are poorly studied. We examined the relationships between first trimester levels of selenium $(\mathrm{Se})$, iron $(\mathrm{Fe})$, zinc $(\mathrm{Zn})$, and copper $(\mathrm{Cu})$, as well as maternal characteristics and pregnancy results. The data came from a Polish prospective cohort of women in a single pregnancy without chronic diseases. A group of 563 women who had a complete set of data, including serum microelements in the 10-14th week was examined, and the following were found: 47 deliveries $<37$ th week; 48 cases of birth weight $<10$ th and 64 newborns $>90$ th percentile; 13 intrauterine growth restriction (IUGR) cases; 105 gestational hypertension (GH) and 15 preeclampsia (PE) cases; and 110 gestational diabetes mellitus (GDM) cases. The microelements were quantified using mass spectrometry. The average concentrations (and ranges) of the elements were as follows: Se: $60.75 \mu \mathrm{g} / \mathrm{L}$ (40.91-125.54); Zn: $618.50 \mu \mathrm{g} / \mathrm{L} \mathrm{(394.04-3238.90);} \mathrm{Cu:} 1735.91 \mu \mathrm{g} / \mathrm{L}$ (883.61-3956.76); and Fe: $1018.33 \mu \mathrm{g} / \mathrm{L}$ (217.55-2806.24). In the multivariate logistic regression, we found that an increase in Se of $1 \mu \mathrm{g} / \mathrm{L}$ reduces the risk of $\mathrm{GH}$ by $6 \%(\mathrm{AOR}=0.94 ; p=0.004)$, the risk of IUGR by $11 \%(\mathrm{AOR}=0.89 ; p=0.013)$, and the risk of birth $<34$ th week by $7 \%$ (but close to the significance) (AOR $=0.93 ; p=0.061$ ). An increase in Fe of $100 \mu \mathrm{g} / \mathrm{L}$ reduces the risk of PE by $27 \%$ $(\mathrm{AOR}=0.73 ; p=0.009)$. In the multivariable linear regression, we found negative strong associations between prepregnancy BMI, Se $(\beta=-0.130 ; p=0.002)$, and Fe $(\beta=-0.164 ; p<0.0001)$, but positive associations with $\mathrm{Cu}(\beta=0.320 ; p<0.000001)$. The relationships between Se and maternal age ( $\beta=0.167 ; p<0.0001)$, Se and smoking $(\beta=-0.106 ; p=0.011)$ and $\mathrm{Cu}$, and gestational age from the 10-14th week ( $\beta=0.142 ; p<0.001)$ were also found. Secondary education was associated with $\mathrm{Zn}(\beta=0.132 ; p=0.004)$ and higher education was associated with $\mathrm{Cu}(\beta=-0.102 ; p=0.023)$. A higher financial status was associated with Fe $(\beta=0.195 ; p=0.005)$. Other relationships were statistically insignificant. Further research is needed to clarify relationships between first trimester microelements and pregnancy complications. In addition, attention should be paid to lifestyle-related and socioeconomic factors that affect microelement levels.
\end{abstract}

Keywords: selenium; antioxidants; microelements; pregnancy; determinants; risk 


\section{Introduction}

Epidemiological data indicate that adverse pregnancy outcomes and pregnancy complications, including preterm births, preeclampsia (PE), gestational diabetes, and fetal growth restriction (IUGR), occur in total in up to $25 \%$ of first pregnancies [1] and these pregnancy results are an important element of public health. They are associated with an increase in maternal and fetal morbidity and/or mortality [2-10] and they may lead to long-term diseases of both the mother and the child, increasing the risk of cardiovascular diseases, obesity, diabetes, and even some cancers, as well as neurodevelopmental disorders in the offspring [7-11]. Early identification of women at risk may be of great importance for improving pregnancy outcomes. Unfortunately, early risk markers of these pregnancy results remain constantly elusive.

Researchers should pay attention to the microelements involved in the oxidative balance, such as selenium (Se), iron (Fe), copper $(\mathrm{Cu})$, and zinc ( $\mathrm{Zn})$ [1]. Importantly, antioxidative and/or anti-inflammatory selenoproteins such as glutathione peroxidases (GPx), thioredoxin reductases (Th-Redx), and selenoproteins $\mathrm{P}$, as well as antioxidative $\mathrm{Cu}, \mathrm{Zn}-\mathrm{SOD}$ (superoxide dismutase) are also active in the uterus [12-15]. The deficiency of these microelements was previously associated with the low activity of these antioxidative systems, which may be the cause of oxidative damage to placental and fetal tissues [12-15]. Inadequate levels of the microelements can affect maternal health and the development of the fetus, and early pregnancy is a particular exposure period. However, a role of the microelements in pregnancy (especially in early pregnancy), as well as their determinants in pregnant women are poorly studied.

The studies conducted earlier were mainly animal studies or retrospective studies in humans. Abnormal levels of $\mathrm{Se}, \mathrm{Fe}, \mathrm{Zn}$, and $\mathrm{Cu}$ were found in women with preeclampsia or gestational diabetes mellitus (GDM) [16-18]. However, these effects may be due to disorders which have already developed, e.g., increased oxidative stress can increase the consumption of antioxidant elements. There are very few prospective studies. In our Polish prospective cohort of women without chronic diseases recruited in the 10-14th week of a single pregnancy, we examined after the end of pregnancy 121 women developing pregnancy-induced hypertension (PIH) vs. 363 matched women remaining normotensive and we found that a higher risk of PIH was associated with lower serum Se levels in the 10-14th week in a statistically significant way [19]. We also found significant but weaker associations between lower $\mathrm{Cu}$ or Fe levels and PIH [20,21]. In the literature, links between lower concentrations of selenium in early pregnancy, and a higher risk of preeclampsia [22,23], preterm birth [5], or birth to infants $<10$ th percentile [24-26] have been also found. However, the results of other prospective studies are divergent and the research methodologies differ [1,24,27], e.g., Basu et al. examined serum microelements in a small cohort of 151 pregnant women with preexisting diabetes mellitus, including 23 cases of preeclampsia [27]; and Mistry et al. examined a group of 126 adolescents, including 19 women giving birth to infants <10th percentile [24]. However, only one pregnancy complication has been evaluated in these studies. Importantly, the relationships between maternal characteristics and microelement levels can affect the risk being investigated and this requires the assessment of multiple variables simultaneously. The impact of excessive BMI, smoking, or sociodemographic indicators on microelement levels was also found in the literature but these factors were not assessed in multifactorial models after adjusting for many confounding variables $[1,19,20,28]$.

Summing up, associations between first trimester microelements and their determinants or pregnancy results are poorly studied. In a joint group and using multivariable statistic models, we assessed the relationships between serum concentrations of four microelements ( $\mathrm{Se}, \mathrm{Fe}, \mathrm{Zn}$, and $\mathrm{Cu}$ ) at the end of the first trimester, as well as main pregnancy outcomes and complications (including gestational age at delivery/preterm births, newborn weight, IUGR, gestational diabetes mellitus (GDM), and pregnancy-induced hypertension (PIH)). The relationships between the microelements, and maternal characteristics (prepregnancy body mass index (BMI), smoking, maternal age, parity, gestational age when microelements were measured, socioeconomic, and demographic characteristics) were also assessed. 


\section{Materials and Methods}

\subsection{Study Population and Method}

The data for the current study came from a prospective cohort of pregnant women. The original cohort consisted of 912 women. In the original cohort the following were found: 65 (7.1\%) cases of preterm birth $<37$ th week; $72(7.9 \%)$ newborns with a birth weight $<10$ th percentile; $99(10.9 \%)$ newborns $>90$ th percentile; 21 (2.3\%) IUGR cases; 137 (15.0\%) women developing pregnancy-induced hypertension (PIH); and 146 (16.0\%) women developing gestational diabetes mellitus (GDM). Blood samples from mothers were taken during recruitment at the 10-14th gestational week and sera were stored at $-80^{\circ} \mathrm{C}$.

The study was performed at the university of obstetric-gynecological and neonatological center (University Hospital in Poznan, Poland, with 6-8 thousand births a year). The study was carried out in accordance with the Helsinki Declaration and was approved by the Bioethics Committee of the Medical University of Poznan, Poland (approval number 769/15), and all the participants signed the Informed Consent Form. The cohort was recruited in 2015-2016; pregnancy results were collected in 2016-2017, and the analysis of data was conducted in 2017-2019.

The criteria for inclusion in this cohort were: Polish Caucasian women of descent from one region (Wielkopolska); aged 18-45 years (at conception); in the 10-14th week of a single pregnancy without aneuploidy; with delivery of a phenotypically normal child $\geq 25$ th week of pregnancy.

The criteria for exclusion in this cohort were: Chronic diseases (apart from being in excessive body mass index), including preexisting diabetes mellitus, hypertension, immunological and inflammatory diseases, thromboembolism, and kidney or liver diseases.

The participants were recruited from pregnant women taking laboratory tests. Information about the study was available to everyone in the hospital laboratory. Participation in the study was proposed to each of 1300 women who declared that they meet the inclusion criteria (in the period of 12 months in 2015-2016). Participation in the study was voluntary. Until this analysis, missing data concerned $388(29.9 \%)$ participants, including women who did not meet the inclusion criteria after the end of pregnancy and women whose data were incomplete.

Data was collected from a questionnaire during recruitment (in the 10-14th week) and the women filled it out themselves (but in the presence of midwives). The information such as maternal age, weight and height, parity (number of deliveries), history of pregnancy, gynecological histories, concurrent diseases, demographic and socioeconomic characteristics, supplements and medications, family history of pregnancy and chronic diseases, smoking, and consumption of alcohol were collected (all women declared no alcohol in pregnancy). Blood samples from mothers were taken during recruitment from fasting women (women were asked to fast a minimum of $4 \mathrm{~h}$ prior to blood collection). Sera were stored at $-80^{\circ} \mathrm{C}$.

Height and prepregnancy weight were self-reported. The mother's height was also measured (in the hospital) before delivery and the values from medical records were included in the study. Prepregnancy body mass index (BMI) for each woman was calculated as a ratio of a weight in kilograms and a height in meters ${ }^{2}\left(\mathrm{~kg} / \mathrm{m}^{2}\right)$, and normal BMI was defined as $18.5-24.99 \mathrm{~kg} / \mathrm{m}^{2}$.

The place of residence included: Village, small town $(<50,000$ inhabitants), and big city ( $>50,000$ inhabitants). Maternal education categories included: Elementary, vocational, secondary, and higher education; education $<12$ years included elementary and vocational education; lower education levels included elementary, vocational, and secondary education. The financial status was assessed by means of a 5-point Likert scale for the question "Is your financial situation (in your household) good enough to meet your needs?", and maternal responses were classified as follows: Lower financial status (for responses: Definitely NO, rather NO, and hard to say) and higher financial status (for responses: Rather YES and definitely YES).

After the end of pregnancy, results were taken from the hospital medical records. Pregnancy outcomes (including birth weight, intrauterine growth restriction, gestational age at birth, fetal 
sex, APGAR results) and pregnancy complications (including pregnancy-induced hypertension and gestational diabetes mellitus) have been recorded.

The aim of the current analysis was to assess the relationships between levels of maternal microelements measured in serum samples from the 10-14 gestational week, and main pregnancy results and maternal characteristics. In the current analysis, a group of 563 women who had a complete set of data, including concentrations of the microelements in the 10-14th week was examined. All data came from our original (primary) cohort of pregnant women $(n=912)$. In the current study, most of the data (together with the concentrations of the elements) came from our previous analysis, in which we examined women who developed pregnancy-induced hypertension and their matched normotensive controls $(n=480)$; cases and controls were matched in terms of: Mother's age ( \pm 2 years), prepregnancy BMI $( \pm 10 \%)$, and smoking [19]. Part of the data $(n=83)$ came from a small pilot analyses conducted among randomly selected normotensive women. Microelements were measured in serum samples after determining the subgroups of women studied (after the end of pregnancy).

In the group of 563 participants the following were found: $47(8.4 \%)$ cases of preterm birth $<37$ th week (vs. 516 childbirth $\geq 37$ th week); 48 (8.5\%) newborns with a birth weight $<10$ th percentile, and $64(11.4 \%)$ newborns $>90$ th percentile (vs. 451 newborns between the 10-90th percentile); $13(2.3 \%)$ IUGR cases; 120 (21.3\%) women developing pregnancy induced hypertension (PIH) (vs. 443 women remaining normotensive); and 110 (19.5\%) women developing gestational diabetes mellitus (GDM) (vs. 453 women without GDM). The frequency of the pregnancy results in the study group was close to the frequency in the originally cohort $[1,2,5,29-31]$.

\subsection{Pregnancy Outcomes and Pregnancy Complications}

Pregnancy outcomes and complications were taken from the hospital medical records.

The gestational age was estimated based on fetal first trimester ultrasound measurements. Crown-rump length (CRL) measurements were used for pregnancy dating in the 10-13th week of gestation. Above week 14th, other measurements are also considered, as well as combinations thereof.

The birth weight was assessed after birth by means of an electronic scale (in grams). For the assessment of categories of birth weight $(<10$ th and $>90$ th percentile), data from a fetal biometry for the Polish population for the gender of the newborn and for gestational age was used [26]. A diagnosis of intrauterine growth restriction (IUGR) was determined in the utero (via an ultrasound).

Pregnancy-induced hypertension (PIH) was defined in accordance with the national guidelines (2015) and the new definition [2], as "arterial pressure equal to and higher than 140/90 $\mathrm{mmHg}$ (on two occasions, at least $4 \mathrm{~h}$ apart, in a sitting position, with an oscillometric device) developed de novo after the 20th week of pregnancy, receding up to 12 weeks after delivery." PIH includes two (main) forms. "Gestational hypertension (GH) was diagnosed if no other disturbance was found; preeclampsia (PE) was diagnosed when any of the following appeared de novo: Proteinuria $(\geq 300 \mathrm{mg} /$ day or $\geq 0.3 \mathrm{~g} / \mathrm{L}$; protein/creatinine ratio $\geq 0.3 ; 1+$ in the strip test); thrombocytopenia $<100 \mathrm{G} / \mathrm{L}$; worsening of renal function; damage to the liver function; pulmonary edema; symptoms from the central nervous system; blurred vision. Intrauterine growth restriction (IUGR) was not one of the criteria of diagnosis". In this cohort, only proteinuria $(\geq 0.3 \mathrm{~g} / \mathrm{L})$ was found in all cases of preeclampsia.

Gestational diabetes mellitus (GDM) was defined in accordance with the national guidelines and the International Association of Diabetes and Pregnancy Study Groups [32]; it was diagnosed based on a 2-h $75 \mathrm{~g}$ oral glucose tolerance test (OGTT) after an overnight fast, conducted between the 24th and 28th gestational weeks. Gestational diabetes GDM-1 was diagnosed when modification of the diet was sufficient to control glucose levels. When additional insulin therapy was required, gestational diabetes GDM-2 was diagnosed. 


\subsection{Determination of Microelements}

The concentrations of the microelements (Se, Fe, $\mathrm{Zn}$, and $\mathrm{Cu}$ ) in serum samples were measured. Blood samples from mothers were taken in the 10-14th week of pregnancy (at recruitment) from participants who reported fasting. Samples of venous blood were collected using serum in Z/7.5 mL tubes (Sarstedt Monovette system; Sarstedt, Nümbrecht, Germany).

The tubes were incubated to clot (at room temperature for at least $30 \mathrm{~min}$ and no longer than $2 \mathrm{~h}$ ) and next, samples were centrifuged (at $1300 \mathrm{G}$ for $12 \mathrm{~min}$ ). Next, sera were stored at $-80{ }^{\circ} \mathrm{C}$ (until analysis, after the end of pregnancy).

Before determination of the microelements, sera were thawed and centrifuged (at $5000 \mathrm{G}$ for $5 \mathrm{~min}$ ). The microelement concentrations were determined by means of the Inductively Coupled Plasma Mass Spectrometer: NexION 350D (PerkinElmer, Shelton, CT, USA). The spectrometer was tuned to achieve the manufacturers' criteria, before an analytical run. Methane was used as a reaction gas.

The instrument was calibrated using an external calibration technique. Calibration standards were prepared from $10 \mu \mathrm{g} / \mathrm{mL}$ of Multi-Element Calibration Standard 3 (PerkinElmer, Shelton, CT, USA) by diluting with a blank reagent to the final concentration of $0.1,0.5,1.0,2.0,5.0$, and $10 \mu \mathrm{g} / \mathrm{L}$ (for Se measurement); 1, 5, 10, and $50 \mu \mathrm{g} / \mathrm{L}$ (for Fe measurement); 1, 5, and $10 \mu \mathrm{g} / \mathrm{L}$ (for Cu measurement); and 1,5 , and $10 \mu \mathrm{g} / \mathrm{L}$ (for Zn measurement). Correlation coefficients for calibration curves were always greater than 0.999 .

The analysis protocol assumed a 100-fold dilution of serum in the blank reagent. The blank reagent consisted of $10 \mathrm{~mL}$ of $65 \%$ Suprapur Grade nitric acid (Merck, Darmstadt, Germany), $0.20 \mathrm{~mL}$ of Triton X-100 (PerkinElmer, Shelton, CT, USA) filled to the mark of a 1-L flask with $>18 \mathrm{M} \Omega / \mathrm{cm}^{2}$ deionized water (Merck Millipore, Burlington, MA, USA). Germanium isotope (Ge74) was set as an internal standard.

The accuracy and precision of measurements were tested using a certified reference material (CRM), Clincheck Plasmonorm Serum Trace Elements Level 1 (Recipe, Munich, Germany). Additionally, internal quality control samples were measured during the analysis. General precision was lower than $5 \%$ relative standard deviation (RSD). The final concentration included a dilution factor and coefficient which was the mean value of two flanking certified reference material concentrations divided by the mean concentration determined by the manufacturer of CRM [19,20,26,33]. Additional information will be provided on request.

\subsection{Statistical Analyses}

Statistical analyses were performed using the Statistica 13 software. Before statistical analyses, the Shapiro-Wilk test was used to assess the normality of the data distribution. Data distributions were not normal and the Mann-Whitney $U$ test was used to compare microelement medians between pregnancy results or between different categories of maternal characteristics ( $p$-value $<0.05$ was considered statistically significant). The medians and interquartile ranges $(25 \%-75 \%)$ or average microelement concentrations (and standard deviation (SD)) were presented.

The impact of microelement levels (as independent variables) on binary pregnancy results (PIH and GDM and their forms, IUGR and preterm births <37th and <34th week) was assessed in the logistic regression. Adjusted odds ratios (AOR) (and 95\% confident intervals (CI)) of pregnancy results for microelement concentrations as continuous variables were calculated in the multivariate logistic regression, and $p$-value was calculated using the Wald test ( $p$-value $<0.05$ was considered to be significant).

The impact of microelement levels (as independent variables) on gestational age at delivery (as a continuous dependent variable) was also assessed in the multivariable linear regression. The inverse analysis for the impact of binary pregnancy results on the microelement levels is additionally presented in the supplement. One can examine the impact of binary variables on the level of biomarker in the multivariable linear regression, which is possible in the multifactorial model that we used (presence or absence of the disease significantly differentiates the marker level). 
The impact of maternal characteristics (as independent variables) on microelement concentrations (as dependent variables) were also evaluated in the multivariable linear regression.

The results of linear regression are presented using the regression coefficient (Beta), the standardized regression coefficient $(\beta)$, the level of significance ( $p$-value $<0.05$ was considered statistically significant), and the determination coefficient $\left(\mathrm{R}^{2}\right)$, which tells what part of the variability of the dependent variable is explained (predicted) by the regression model. Values of $95 \%$ confidence interval (95\% CI) and adjusted $\mathrm{R}^{2}\left(\operatorname{adj} \mathrm{R}^{2}\right)$, which take into account the number of variables in the model were also calculated (data not shown).

The relationships between microelement concentrations and maternal characteristics were evaluated after adjustment for maternal age, prepregnancy BMI, and gestational age at recruitment (variables previously identified as significantly affecting microelement levels in the univariable linear regression). However, the assessed independent variable has always been excluded from the confounding variables. These results were also sustained after PIH was included in the confounding variables (data not shown).

The relationships between microelement levels and PIH, GDM (and their forms), and IUGR, were evaluated after adjusting for maternal age, prepregnancy BMI, gestational age at recruitment, prior $\mathrm{PIH}$, assisted reproductive technology, smoking at recruitment, parity, and education $<12$ years. The results for preterm birth risk $(<37$ th and $<34$ th week) were obtained after adjusting for maternal age, prepregnancy BMI, gestational age at recruitment, preeclampsia, delivery by caesarean section, parity, fetal sex, and smoking; the results were not sustained in models with premature rupture of membranes (PROM).

\section{Results}

General characteristics of participants $(n=563)$ are presented in Table 1 . The average age was 34.8 years (range 18-45 years), and the average gestational age during recruitment and measurement of microelement concentrations was 12.1 weeks (range 10-14th week).

Table 1. General characteristics of the whole group.

\begin{tabular}{|c|c|c|c|}
\hline \multicolumn{4}{|c|}{ General Characteristics } \\
\hline Microelements * & $\mathbf{N}$ & Median & ( $25 \%-75 \%$ ranges) \\
\hline Selenium $(\mu \mathrm{g} / \mathrm{L})$ & 563 & 60.27 & $55.08-65.04$ \\
\hline Iron $(\mu \mathrm{g} / \mathrm{L})$ & 563 & 993.94 & $801.20-1208.42$ \\
\hline Zinc $(\mu \mathrm{g} / \mathrm{L})$ & 563 & 606.61 & $548.54-662.89$ \\
\hline Copper ( $\mu \mathrm{g} / \mathrm{L})$ & 563 & 1727.10 & 1532.84-1923.11 \\
\hline Maternal characteristics & & Mean $( \pm S D)$ or $n$ & Range or (\%) \\
\hline Maternal age (years) & 563 & $34.8(4.4)$ & $18-45$ \\
\hline Maternal age $\geq 35$ years & 563 & 358 & $(63.6 \%)$ \\
\hline Number of prior births (n) & 563 & $0.87(0.91)$ & $0-5$ \\
\hline Primiparous & 563 & 229 & $(40.7 \%)$ \\
\hline Gestational age at recruitment (week) & 563 & $12.1(0.9)$ & $10-14$ \\
\hline Prepregnancy BMI $\left(\mathrm{kg} / \mathrm{m}^{2}\right)$ & 563 & $24.9(4.7)$ & $16.5-42.9$ \\
\hline Prepregnancy BMI $\geq 25 \mathrm{~kg} / \mathrm{m}^{2}$ & 563 & 220 & $(39.1 \%)$ \\
\hline Smokers \# & 563 & 36 & $(6.4 \%)$ \\
\hline Lower education levels \#\# & 468 & 175 & $(37.4 \%)$ \\
\hline Lower financial status \#\#\# & 214 & 83 & $(38.8 \%)$ \\
\hline Pregnancy outcomes & & Mean $( \pm S D)$ or $n$ & Range or (\%) \\
\hline Fetal sex-Son & 563 & 294 & $(52.2 \%)$ \\
\hline Gestational age at birth (week) & 563 & $38.5(2.0)$ & $25-42$ \\
\hline Childbirth $<37$ th week & 563 & 47 & $(8.4 \%)$ \\
\hline Childbirth $<34$ th week & 563 & 17 & $(3.0 \%)$ \\
\hline Childbirth $\geq 37$ th week & 563 & 516 & $(91.7 \%)$ \\
\hline
\end{tabular}


Table 1. Cont.

\begin{tabular}{|c|c|c|c|}
\hline \multicolumn{4}{|c|}{ General Characteristics } \\
\hline Pregnancy outcomes & & Mean $( \pm S D)$ or $n$ & Range or $(\%)$ \\
\hline Birth weight $(\mathrm{g})$ & 563 & $3315.9(618.2)$ & $495.0-5200.0$ \\
\hline Birth weight $<10$ th percentile & 563 & 48 & $(8.5 \%)$ \\
\hline Birth weight $>90$ th percentile & 563 & 64 & $(11.4 \%)$ \\
\hline Birth weight between the $10-90$ th percentile & 563 & 451 & $(80.1 \%)$ \\
\hline Intrauterine growth restriction (IUGR) & 563 & 13 & $(2.3 \%)$ \\
\hline Pregnancy-induced hypertension $(\mathrm{PIH})$ * & 563 & 120 & $(21.3 \%)$ \\
\hline Normotensive controls & 563 & 443 & $(78.7 \%)$ \\
\hline Gestational diabetes mellitus (GDM) ** & 563 & 110 & $(19.5 \%)$ \\
\hline Women without GDM & 563 & 453 & $(80.5 \%)$ \\
\hline
\end{tabular}

* Normal ranges for the microelements (for not pregnant women $>18$ years) according to laboratory data in the

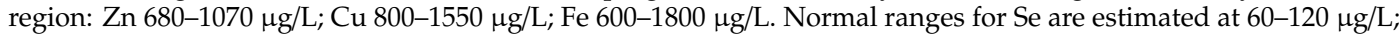
\# smokers during recruitment; \#\# elementary, vocational, and secondary education; \#\#\# in the 5-point Likert scale (lower status included 1-2-3 level); * pregnancy-induced hypertension (PIH) included 105 cases of gestational hypertension (GH) and 15 cases of preeclampsia (PE); ** gestational diabetes mellitus (GDM) included 90 cases with dietary modification (GDM-1) and 20 cases with additional insulin therapy (GDM-2).

The average prepregnancy BMI was $24.9 \mathrm{~kg} / \mathrm{m}^{2}\left(\right.$ range $\left.16.5-42.9 \mathrm{~kg} / \mathrm{m}^{2}\right)$, and the average gestational age at birth was 38.5 weeks (range 25-42th week). In the whole group (where important risk factors for adverse pregnancy outcomes have been excluded), 15 (2.7\%) cases of preeclampsia (PE) and $20(3.6 \%)$ cases of gestational diabetes mellitus with insulin therapy (GDM-2) were found (Table 1).

The relationships between maternal features and the microelements are presented in Tables 2-4 and Table S1. The average microelement concentrations (and SD) were presented in Table 2, but medians were compared between subgroups (Table S1). Primiparous had a statistically significantly higher $\mathrm{Zn}$ levels compared to multiparous.

Table 2. Maternal characteristics and microelement concentrations (in serum from the 10-14th week of pregnancy).

\begin{tabular}{|c|c|c|c|c|c|}
\hline \multicolumn{6}{|c|}{ Microelement Concentrations $(\mu \mathrm{g} / \mathrm{L}) *($ Mean \pm SD) } \\
\hline & & $\begin{array}{l}\text { SELENIUM } \\
(\mathrm{Se})\end{array}$ & $\begin{array}{c}\text { IRON } \\
(\mathrm{Fe})\end{array}$ & $\begin{array}{c}\text { ZINC } \\
(\mathrm{Zn})\end{array}$ & $\begin{array}{c}\text { COPPER } \\
(\mathrm{Cu})\end{array}$ \\
\hline Maternal Characteristics & $\mathbf{n}$ & & & & \\
\hline \multicolumn{6}{|l|}{ Parity } \\
\hline Primiparous & 229 & $60.87(10.15)$ & $1027.89(338.26)$ & $640.08(209.67)$ & $1715.10(229.00)$ \\
\hline Multiparous & 334 & $60.67(7.00)$ & $1011.78(344.66)$ & $603.69(84.32)$ & $1750.18(293.38)$ \\
\hline$p$-value & & 0.328 & 0.730 & 0.007 & 0.065 \\
\hline \multicolumn{6}{|l|}{ Maternal age (years) } \\
\hline Age $\geq 35$ & 358 & $61.56(41.14)$ & $1003.07(319.75)$ & $614.15(96.32)$ & $1737.13(312.94)$ \\
\hline Age $<35$ & 205 & $59.34(40.91)$ & $1044.98(376.72)$ & $626.08(212.83)$ & $1733.78(335.20)$ \\
\hline$p$-value ** & & 0.0002 & 0.468 & 0.862 & 0.652 \\
\hline \multicolumn{6}{|l|}{ Prepregnancy BMI $\left(\mathrm{kg} / \mathrm{m}^{2}\right)$} \\
\hline $\mathrm{BMI} \geq 25$ & 220 & $59.84(44.39)$ & $996.95(335.21)$ & $629.17(209.65)$ & $1846.21(357.11)$ \\
\hline $\mathrm{BMI}<25$ & 343 & $61.34(40.91)$ & $1051.29(342.50)$ & $611.65(92.16)$ & $1665.16(273.38)$ \\
\hline$p$-value ** & & 0.006 & 0.002 & 0.893 & $<0.00001$ \\
\hline \multicolumn{6}{|l|}{ Smoking at recruitment } \\
\hline Yes & 36 & $56.79(40.91)$ & $1053.31(369.45)$ & $622.20(89.34)$ & $1718.79(272.24)$ \\
\hline No & 527 & $61.02(42.68)$ & $1015.94(340.14)$ & $618.24(152.86)$ & 1737.08 (324.18) \\
\hline$p$-value ** & & 0.009 & 0.612 & 0.353 & 0.645 \\
\hline \multicolumn{6}{|l|}{ Education } \\
\hline Higher & 293 & $61.59(42.68$ & $1023.05(334.68)$ & 606.79 (87.16) & $1699.65(284.66)$ \\
\hline Other (Lower levels) & 175 & $59.62(40.91)$ & $1030.44(361.58)$ & $640.13(227.81)$ & $1798.29(340.71)$ \\
\hline$p$-value ${ }^{* *}$ & & 0.0005 & 0.720 & 0.197 & 0.001 \\
\hline
\end{tabular}


Table 2. Cont.

\begin{tabular}{|c|c|c|c|c|c|}
\hline \multicolumn{6}{|c|}{ Microelement Concentrations $(\mu \mathrm{g} / \mathrm{L}) *($ Mean \pm SD) } \\
\hline & & $\begin{array}{l}\text { SELENIUM } \\
\text { (Se) }\end{array}$ & $\begin{array}{c}\text { IRON } \\
\text { (Fe) }\end{array}$ & $\begin{array}{c}\text { ZINC } \\
\text { (Zn) }\end{array}$ & $\begin{array}{c}\text { COPPER } \\
(\mathrm{Cu})\end{array}$ \\
\hline Maternal Characteristics & $\mathbf{n}$ & & & & \\
\hline \multicolumn{6}{|l|}{ Financial status $* * *$} \\
\hline Higher status (4-5) & 131 & $61.91(40.91)$ & $1106.05(337.95)$ & $614.10(92.51)$ & $1736.00(300.54)$ \\
\hline Lower status (1-2-3) & 83 & $59.30(44.85)$ & $933.87(319.38)$ & $641.96(311.84)$ & $1799.13(376.59)$ \\
\hline$p$-value ** & & 0.006 & 0.001 & 0.610 & 0.394 \\
\hline \multicolumn{6}{|l|}{ Place of residence } \\
\hline Village & 160 & 60.08 (7.17) & $1027.58(345.65)$ & $629.20(229.31)$ & $1748.43(295.50)$ \\
\hline Other & 402 & $61.02(8.87)$ & $1015.55(340.66)$ & 614.35 (102.14) & $1731.30(331.03)$ \\
\hline$p$-value & & 0.324 & 0.910 & 0.767 & 0.516 \\
\hline
\end{tabular}

* Microelement concentrations were measured in serum samples from the 10-14th gestational week; ** $p$-value was obtained using the Mann-Whitney $\mathrm{U}$ test and medians were compared ( $p<0.05$ was considered to be significant); *** financial status in the 5-point Likert scale (lower status included 1-2-3th levels and higher status included 4-5th levels); BMI: Body mass index.

Statistically significant relationships between lower selenium (Se) levels and several maternal characteristics (prepregnancy BMI $\geq 25 \mathrm{~kg} / \mathrm{m}^{2}$, smoking, maternal age $<35$ years, lower education level, and lower financial status level) were found. Significant relationships between lower Fe or higher $\mathrm{Cu}$ levels, and prepregnancy BMI $\geq 25 \mathrm{~kg} / \mathrm{m}^{2}$ were also found. Significant relationships between levels of $\mathrm{Fe}, \mathrm{Zn}$, and $\mathrm{Cu}$, and education and financial levels were found.

The impact of maternal features (as independent variables) on microelements in the multivariable model is presented in Table 3. In the multivariable linear regression, Se levels were associated positively with maternal age $(p<0.0001)$, but the women were aged 18-45. Selenium (Se) levels were also associated negatively with smoking $(p=0.011)$. Copper $(\mathrm{Cu})$ levels were associated positively with the gestational age at measurement of microelements (from the 10-14th week) $(p<0.001)$. Prepregnancy BMI was associated negatively with Se $(p=0.002)$ and Fe levels $(p<0.0001)$ but positively with $\mathrm{Cu}$ levels $(p<0.000001)$.

Table 3. The adjusted relationships between maternal features and microelement levels.

\begin{tabular}{|c|c|c|c|c|}
\hline \multicolumn{5}{|c|}{$\begin{array}{c}\text { Impact of Maternal Features on Microelement Levels } \\
\text { in the Multivariable Linear Regression \# }\end{array}$} \\
\hline & Beta * & $\beta * *$ & $p * * *$ & $\mathbf{R}^{2 * * * *}$ \\
\hline \multicolumn{5}{|l|}{ SELENIUM (Se) } \\
\hline Maternal age (years) & 0.319 & 0.167 & 0.00007 & 0.040 \\
\hline Number of prior births & -0.514 & -0.056 & 0.207 & 0.043 \\
\hline Prepregnancy BMI $\left(\mathrm{kg} / \mathrm{m}^{2}\right)$ & -0.232 & -0.130 & 0.002 & 0.040 \\
\hline Gestational age at recruitment (weeks) & 0.405 & 0.041 & 0.325 & 0.042 \\
\hline Smoking at recruitment & -3.627 & -0.106 & 0.011 & 0.051 \\
\hline \multicolumn{5}{|l|}{ IRON (Fe) } \\
\hline Maternal age (years) & -3.866 & -0.050 & 0.236 & 0.029 \\
\hline Number of prior births & -11.635 & -0.031 & 0.458 & 0.028 \\
\hline Prepregnancy BMI (kg/m²) & -11.871 & -0.164 & 0.00009 & 0.027 \\
\hline Gestational age at recruitment (weeks) & 17.545 & 0.044 & 0.296 & 0.025 \\
\hline Smoking at recruitment & 50.478 & 0.036 & 0.387 & 0.028 \\
\hline \multicolumn{5}{|l|}{ ZINC (Zn) } \\
\hline Maternal age (years) & -1.579 & -0.046 & 0.275 & 0.004 \\
\hline Number of prior births & -13.052 & -0.080 & 0.060 & 0.008 \\
\hline Prepregnancy BMI $\left(\mathrm{kg} / \mathrm{m}^{2}\right)$ & 1.421 & 0.045 & 0.288 & 0.002 \\
\hline Gestational age at recruitment (weeks) & -11.634 & -0.066 & 0.118 & 0.006 \\
\hline Smoking at recruitment & 2.417 & 0.004 & 0.925 & 0.002 \\
\hline
\end{tabular}


Table 3. Cont.

\begin{tabular}{ccccc}
\hline \multicolumn{6}{c}{$\begin{array}{c}\text { Impact of Maternal Features on Microelement Levels } \\
\text { in the Multivariable Linear Regression \# }\end{array}$} \\
\hline & Beta * & $\boldsymbol{\beta}^{* *}$ & $p^{* * *}$ & $\mathbf{R}^{2 * * * *}$ \\
\hline COPPER (Cu) & & & & \\
\hline Maternal age (years) & -2.741 & -0.038 & 0.346 & 0.127 \\
Number of prior births & -2.326 & -0.007 & 0.868 & 0.126 \\
Prepregnancy BMI (kg/m $\left.{ }^{2}\right)$ & 21.760 & 0.320 & $<0.000001$ & 0.126 \\
Gestational age at recruitment (weeks) & 53.773 & 0.142 & 0.0004 & 0.126 \\
Smoking at recruitment & -34.088 & -0.026 & 0.512 & 0.126 \\
\hline
\end{tabular}

\# Relationships between variables were calculated after adjusting for maternal age, prepregnancy BMI, and gestational age at recruitment (variables identified in the univariable linear regression as significantly affecting microelement levels) but the assessed independent variable has always been excluded from the confounding variables; ${ }^{*}$ Beta: Unstandardized regression coefficient ${ }^{* *} \beta$ : Standardized regression coefficient; ${ }^{* * *} p<0.05$ was considered to be significant; ${ }^{* * *} R^{2}$ : Coefficient of determination.

The impact of sociodemographic indicators (as independent variables) on microelements in the multivariable model is presented in Table 4 . In the multivariable linear regression, zinc $(\mathrm{Zn})$ was associated positively with secondary education $(p=0.004)$, and $\mathrm{Cu}$ was associated negatively with higher education $(p=0.023)$. Iron $(\mathrm{Fe})$ was associated positively with a higher financial status $(p=0.005)$.

Table 4. The adjusted relationships between sociodemographic indicators and microelement levels.

\begin{tabular}{|c|c|c|c|c|}
\hline \multicolumn{5}{|c|}{$\begin{array}{c}\text { Impact of Sociodemographic Indicators on Microelement Levels } \\
\text { in the Multivariable Linear Regression \# }\end{array}$} \\
\hline & Beta * & $\beta * *$ & $p^{* * *}$ & $\mathbf{R}^{2 * * * *}$ \\
\hline \multicolumn{5}{|l|}{ SELENIUM (Se) } \\
\hline Higher education & 1.332 & 0.080 & 0.082 & 0.085 \\
\hline Secondary education & -0.826 & -0.045 & 0.316 & 0.081 \\
\hline Education $<12$ years & -1.467 & -0.057 & 0.214 & 0.082 \\
\hline Higher financial status \# & 1.835 & 0.114 & 0.093 & 0.126 \\
\hline Village & -0.892 & -0.048 & 0.252 & 0.044 \\
\hline Town $<50,000$ inhabitants & 0.416 & 0.023 & 0.583 & 0.042 \\
\hline City $>50,000$ inhabitants & 0.381 & 0.022 & 0.594 & 0.042 \\
\hline \multicolumn{5}{|l|}{ IRON (Fe) } \\
\hline Higher education & -35.44 & -0.050 & 0.288 & 0.036 \\
\hline Secondary education & 61.17 & 0.078 & 0.088 & 0.039 \\
\hline Education $<12$ years & -41.675 & -0.038 & 0.418 & 0.035 \\
\hline Higher financial status \# & 135.790 & 0.195 & 0.005 & 0.091 \\
\hline Village & 16.646 & 0.022 & 0.601 & 0.031 \\
\hline Town $<50,000$ inhabitants & -2.209 & -0.003 & 0.943 & 0.031 \\
\hline City $>50,000$ inhabitants & -12.061 & -0.017 & 0.680 & 0.031 \\
\hline \multicolumn{5}{|l|}{ ZINC (Zn) } \\
\hline Higher education & -30.515 & -0.095 & 0.046 & 0.017 \\
\hline Secondary education & 46.800 & 0.132 & 0.004 & 0.026 \\
\hline Education $<12$ years & -23.800 & -0.048 & 0.313 & 0.011 \\
\hline Higher financial status \# & -28.448 & -0.067 & 0.351 & 0.004 \\
\hline Village & 16.472 & 0.050 & 0.242 & 0.011 \\
\hline Town $<50,000$ inhabitants & -8.182 & -0.025 & 0.550 & 0.009 \\
\hline City $>50,000$ inhabitants & -6.594 & -0.022 & 0.610 & 0.009 \\
\hline \multicolumn{5}{|l|}{ COPPER $(\mathrm{Cu})$} \\
\hline Higher education & -65.022 & -0.102 & 0.023 & 0.131 \\
\hline Secondary education & 55.496 & 0.079 & 0.071 & 0.127 \\
\hline Education $<12$ years & 40.315 & 0.041 & 0.361 & 0.122 \\
\hline Higher financial status \# & -6.586 & -0.010 & 0.884 & 0.162 \\
\hline
\end{tabular}


Table 4. Cont.

\begin{tabular}{ccccc}
\hline $\begin{array}{c}\text { Impact of Sociodemographic Indicators on Microelement Levels } \\
\text { in the Multivariable Linear Regression \# }\end{array}$ \\
\hline & Beta * & $\boldsymbol{\beta}^{* *}$ & $p^{* * *}$ & $\mathbf{R}^{2 * * *}$ \\
\hline COPPER (Cu) & & & & \\
\hline Village & -7.255 & -0.010 & 0.798 & 0.127 \\
Town $<50,000$ inhabitants & 14.082 & 0.020 & 0.610 & 0.127 \\
City $>50,000$ inhabitants & -6.431 & -0.010 & 0.805 & 0.127 \\
\hline
\end{tabular}

\# Relationships between variables were calculated in the multivariable linear regression after adjusting for maternal age, prepregnancy BMI, and gestational age at recruitment (variables identified in the univariable linear regression as significantly affecting microelement levels); \# financial status in the 5-point Likert scale (lower status included 1-2-3th levels and higher status included 4-5th levels); ${ }^{*}$ Beta: Unstandardized regression coefficient ${ }^{* *} \beta$ : Standardized regression coefficient.; ${ }^{* * *} p<0.05$ was considered to be significant; ${ }^{* * *} \mathrm{R}^{2}$ : Coefficient of determination.

The relationships between microelements and pregnancy results are presented in Tables 5 and 6 and Table S2.

Table 5. The microelement concentrations (in the 10-14th week of pregnancy) and pregnancy results.

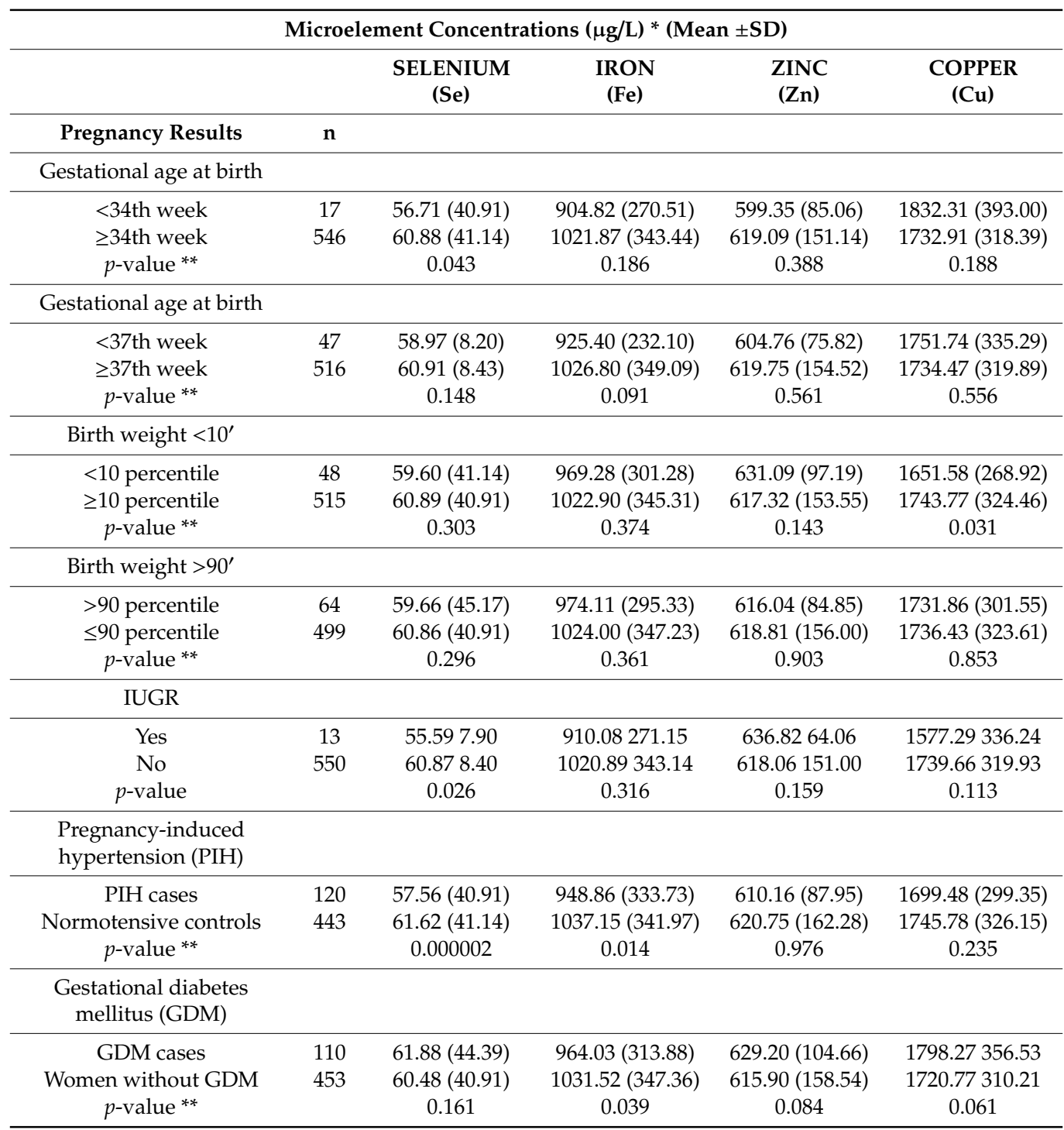

* Microelement concentrations were measured in serum samples from the 10-14th gestational week; ${ }^{* *} p$-value was obtained using the nonparametric Mann-Whitney U test $(p<0.05$ was considered to be significant; IUGR: Intrauterine growth restriction; PIH: Pregnancy-induced hypertension (105 cases of gestational hypertension and 15 cases of preeclampsia); GDM: Gestational diabetes mellitus (90 cases of GDM-1 and 20 cases of GDM-2). 
Table 6. The adjusted odds ratios of pregnancy results for levels of microelements.

\begin{tabular}{|c|c|c|c|}
\hline \multicolumn{4}{|c|}{ Adjusted Odds Ratios of Pregnancy Results } \\
\hline & AOR * & (95\% CI:) & $p^{* *}$ \\
\hline \multicolumn{4}{|l|}{ For selenium (Se) concentrations (for $1 \mu \mathrm{g} / \mathrm{L}$ ) } \\
\hline Pregnancy-induced hypertension (PIH) & 0.95 & $0.91-0.99$ & 0.011 \\
\hline Isolated gestational hypertension $(\mathrm{GH})$ & 0.94 & $0.90-0.98$ & 0.004 \\
\hline Preeclampsia $(\mathrm{PE})$ & 1.03 & $0.95-1.10$ & 0.490 \\
\hline IUGR & 0.89 & $0.82-0.98$ & 0.013 \\
\hline Gestational Diabetes Mellitus (GDM) & 1.01 & $0.97-1.04$ & 0.748 \\
\hline GDM-1 & 1.01 & $0.97-1.04$ & 0.760 \\
\hline GDM-2 & 1.00 & $0.92-1.08$ & 0.914 \\
\hline Preterm birth $<34$ week & 0.93 & $0.86-1.00$ & 0.061 \\
\hline Preterm birth $<37$ week & 0.97 & $0.92-1.01$ & 0.117 \\
\hline \multicolumn{4}{|l|}{ For iron $(\mathrm{Fe})$ concentrations (for $100 \mu \mathrm{g} / \mathrm{L}$ ) } \\
\hline Pregnancy-induced hypertension (PIH) & 0.93 & $0.85-1.02$ & 0.115 \\
\hline Isolated gestational hypertension $(\mathrm{GH})$ & 0.98 & $0.90-1.07$ & 0.655 \\
\hline Preeclampsia (PE) & 0.73 & $0.57-0.92$ & 0.009 \\
\hline IUGR & 0.89 & $0.74-1.07$ & 0.222 \\
\hline Gestational Diabetes Mellitus GDM & 0.94 & $0.86-1.01$ & 0.108 \\
\hline GDM-1 & 0.92 & $0.84-1.00$ & 0.056 \\
\hline GDM-2 & 1.04 & $0.87-1.22$ & 0.687 \\
\hline Preterm birth $<34$ week & 0.96 & $0.81-1.14$ & 0.644 \\
\hline Preterm birth $<37$ week & 0.94 & $0.85-1.04$ & 0.258 \\
\hline \multicolumn{4}{|l|}{ For zinc (Zn) concentrations (for $100 \mu \mathrm{g} / \mathrm{L}$ ) } \\
\hline Pregnancy-induced hypertension (PIH) & 0.86 & $0.67-1.10$ & 0.229 \\
\hline Isolated gestational hypertension $(\mathrm{GH})$ & 0.90 & $0.73-1.11$ & 0.331 \\
\hline Preeclampsia (PE) & 0.72 & $0.37-1.38$ & 0.323 \\
\hline IUGR & 1.05 & $0.83-1.34$ & 0.680 \\
\hline Gestational Diabetes Mellitus GDM & 1.00 & $0.86-1.17$ & 0.984 \\
\hline GDM-1 & 0.97 & $0.80-1.18$ & 0.784 \\
\hline GDM-2 & 1.08 & $0.85-1.37$ & 0.527 \\
\hline Preterm birth $<34$ week & 0.84 & $0.48-1.46$ & 0.532 \\
\hline Preterm birth $<37$ week & 0.91 & $0.66-1.26$ & 0.575 \\
\hline \multicolumn{4}{|l|}{ For copper $(\mathrm{Cu})$ concentrations (for $100 \mu \mathrm{g} / \mathrm{L}$ ) } \\
\hline Pregnancy-induced hypertension (PIH) & 0.93 & $0.85-1.02$ & 0.138 \\
\hline Isolated gestational hypertension $(\mathrm{GH})$ & 0.95 & $0.86-1.04$ & 0.252 \\
\hline Preeclampsia (PE) & 0.95 & $0.78-1.15$ & 0.597 \\
\hline IUGR & 0.83 & $0.67-1.02$ & 0.075 \\
\hline Gestational Diabetes Mellitus GDM & 1.04 & $0.96-1.13$ & 0.371 \\
\hline GDM-1 & 1.04 & $0.96-1.14$ & 0.332 \\
\hline GDM-2 & 1.01 & $0.83-1.21$ & 0.952 \\
\hline Preterm birth $<34$ week & 1.08 & $0.92-1.26$ & 0.336 \\
\hline Preterm birth <37 week & 0.99 & $0.90-1.10$ & 0.901 \\
\hline
\end{tabular}

* AOR: Adjusted odds ratios calculated in the multivariate logistic regression; ${ }^{* *} p$-value obtained using the Wald test $(p<0.05$ was considered to be significant); the results for risk of IUGR were obtained after adjusting for maternal age, prepregnancy BMI, gestational age at recruitment, smoking, parity, prior PIH, assisted reproductive technology; the results for risk of PIH and GDM were obtained in the same model + education level < 12 years; the results for risk of preterm births ( $<37$ th and $<34$ th week) were obtained after adjusting for maternal age, prepregnancy BMI, gestational age at recruitment, smoking, preeclampsia, delivery by caesarean section, parity, and fetal sex (the results were not sustained in models with PROM); CI: Confidence intervals.

The average microelement concentrations (and SD) are presented in Table 5, but medians were compared (Table S2). Women developing pregnancy-induced hypertension (PIH) had significantly lower Se levels compared to the normotensive women $(p<0.001)$. Other relationships were statistically significant but weaker: Lower Se levels in women delivering in $<34$ th compared to deliveries $\geq 34$ th 
week $(p=0.043)$; lower Se levels in IUGR cases compared to controls $(p=0.026)$; lower Fe levels in PIH cases compared to normotensive women $(p=0.014)$; and lower Fe levels in gestational diabetes mellitus (GDM) cases compared to women without GDM ( $p=0.039)$. Importantly, lower levels of maternal $\mathrm{Se}, \mathrm{Fe}$, and $\mathrm{Cu}$ were found simultaneously for birth weight $<10$ th and $>90$ th percentile compared to their controls.

The impact of microelements (as independent variables) on binary pregnancy results in the multivariate model is presented in Table 6. After adjusting for many risk-related variables in the multivariate logistic regression, we found that an increase in Se concentrations of $1 \mu \mathrm{g} / \mathrm{L} \mathrm{reduces}$ the risk of pregnancy-induced hypertension $(\mathrm{PIH})$ and isolated gestational hypertension $(\mathrm{GH})$ by $5 \%$ $(p=0.011)$ and $6 \%(p=0.004)$, respectively. An increase in Se concentrations of $1 \mu \mathrm{g} / \mathrm{L}$ reduces the risk of IUGR by $11 \%(p=0.013)$, and the results for preterm birth $<34$ th week were close to the significance $(p=0.061)$. Among other microelements: An increase in Fe of $100 \mu \mathrm{g} / \mathrm{L}$ reduces the risk of preeclampsia by $27 \%(p=0.009)$. The adjusted relationships between microelements and gestational diabetes (GDM) were statistically insignificant, but an increase in Fe of $100 \mu \mathrm{g} / \mathrm{L}$ reduces the risk of GDM- 1 by $8 \%$ and close to the significance $(p=0.056)$.

The same relationships were calculated in the multivariable linear regression (Table S3) and adjusted results were similar: For the negative relationships between Se levels and PIH $(\beta=-0.178$; $p<0.001)$, GH $(\beta=-0.175 ; p<0.001)$, and IUGR $(\beta=-0.095 ; p=0.022)$. The adjusted relationships between Se and gestational age at birth were positive $(\beta=0.083 ; p=0.044)$ but the results were not sustained in the models with premature rupture of membranes (PROM). The relationships between Fe and preeclampsia also were significant and negative $(\beta=-0.094 ; p=0.026)$. Additionally (Table S3), we found that levels of $\mathrm{Cu}$ were associated negatively with $\mathrm{PIH}(\beta=-0.098 ; p=0.030)$. Negative relationships between Fe and GDM-1 were insignificant $(\beta=-0.051 ; p=0.229)$, but positive relationships between $\mathrm{Cu}$ and GDM-1 were close to the significance $(\beta=0.076 ; p=0.057)$.

The short characteristics of mothers in the case groups (PIH or preterm birth) and their controls are presented in Table S4.

\section{Discussion}

In this study, heathy women with a single pregnancy were recruited in the 10-14th week. After the end of pregnancy, outcomes were recorded. For 563 women, the microelement measurements (in serum samples collected in the 10-14th week) were available.

In the analyses of pregnancy results, strong statistically significant lower levels of Se in women developing pregnancy-induced hypertension (PIH) (including isolated gestational hypertension $(\mathrm{GH})$ ) compared to the normotensive women were found $(p<0.001)$, and these relationships were sustained in the multivariable models (Tables 5 and 6 and Table S3). Other relationships were statistically significant but weaker: Lower Se levels in women delivering in $<34$ th compared to deliveries $\geq 34$ th week; lower Se levels in IUGR cases compared to controls; lower Fe levels in PIH/preeclampsia cases compared to normotensive women (Tables 5 and 6 and Table S3).

The relationships between lower Fe levels and gestational diabetes mellitus (GDM) compared to women without GDM (Table 5) were not sustained in the multivariable models but were close to the significance (Table 6). After adjusting for many risk-related variables, positive relationships between $\mathrm{Cu}$ and GDM-1 also were close to the significance. Other relationships were statistically insignificant in the models we used.

At the same time, the determinants of microelement levels in early pregnancy were: Prepregnancy BMI (for Se, Fe, and Cu), smoking (for Se), maternal age (for Se), and gestational age between 10-14th week (for $\mathrm{Cu}$ ), as well as lower education (for $\mathrm{Zn}$ and $\mathrm{Cu}$ ) and financial status (for $\mathrm{Fe}$ ).

In the literature, there is little prospective research on this topic.

The most frequently studied form of pregnancy-induced hypertension (PIH) is preeclampsia. Among prospective studies, the development of preeclampsia was associated with lower Se levels in a study by Ghaemi et al. [22] and Rayman et al. [22,23]. The prospective role of lower Cu levels 
in predicting preeclampsia were found by Basu et al. and Ugwuja et al. [27,34]. In the very small pilot prospective study, Tande et al. found statistically lower maternal first trimester serum iron (Fe) levels in the women who subsequently developed gestational hypertension, compared to controls [35]. In our previous case-control analyses in matched groups, women in the lowest (Q1) quartile of Se concentrations compared to the women in the highest (Q4) quartile had a 15 times higher PIH risk, in the subgroup of women with the normal prepregnancy BMI [19]. Women in lower quartiles (Q1-Q2) of Fe or $\mathrm{Cu}$ levels (compared to the highest Q4 quartiles) also had a higher risk of PE or PIH/GH respectively, but the results were weaker [20,21].

Preterm birth was associated with lower Se levels in early pregnancy in a study by Rayman et al. [5]. Retrospective studies also showed lower serum Se levels in pregnant women undergoing preterm birth compared to the term group [36,37]. Lower Se levels were also found in women delivering newborns with IUGR [12].

Gestational diabetes mellitus (GDM) was not prospectively associated with first trimester maternal $\mathrm{Se}, \mathrm{Cu}, \mathrm{Zn}$, and Fe levels [1,28]. In women with GDM (in retrospective studies), the relationships between higher levels of plasma $\mathrm{Cu}$ and GDM were found $[17,18]$. Retrospective studies indicate that there are discrepancies in the relationships between Fe, Se, and Zn, and GDM risk [38-41].

The meta-analyses indicate that the relationships between lower levels of micronutrients and SGA (birth weight $<10$ th percentile) are inconsistent and weak [42]. Among the few prospective studies, relationships between lower levels of Se and SGA were found by Mistry et al. and Bogden et al. [24,25]. Our previous study in matched groups also showed the relationships between lower Se levels in early pregnancy and a higher risk of SGA [26]. However, results of other studies are divergent $[1,28]$. Choi et al. found no relationship between lower Se levels and a higher SGA risk (after adjusting for all the trimesters of pregnancy); but they found that lower Se levels were associated with a higher birth weight [28]. Our earlier analysis also showed the relationships between lower Se levels in early pregnancy, and a higher LGA risk (large-for-gestational age birth weight) [33].

In our group of 563 participants (in the current analysis), the frequency of the pregnancy outcomes $(8.4 \%$ of the deliveries were $<37$ th week; $8.5 \%$ of the women gave birth to newborn $<10$ th percentile, and $11.4 \%$ gave birth to newborn $>90$ th percentile) was close to the frequency in other Polish studies $[43,44]$. In our analysis, the frequency of main complications $(21.3 \%$ of the women have developed PIH and $19.5 \%$ have developed GDM) was about 2-4 times higher compared to the frequency in several Polish studies $[43,45,46]$. At the same time, among our participants, $40.7 \%$ of the women were primiparous, $39.1 \%$ had prepregnancy BMI $\geq 25 \mathrm{~kg} / \mathrm{m}^{2}$, and $63.6 \%$ were $\geq 35$ years. Firstly, such a "structure" of our group may result from the fact that our study was conducted in the third-degree reference center, to which women with risk factors apply. These women with risk factors are also more willing to participate in additional research. Secondly, our group included participants from our two previous analyses based on data from the common primary cohort, but most of the data $(n=480)$ came from the analysis of PIH cases and their matched normotensive controls. Importantly, we also obtained our results after correcting for PIH cases (data not shown).

Our prospective cohort was recruited with an exclusion of multiple pregnancy and chronic diseases such as preexisting hypertension or diabetes mellitus, immunological and inflammatory diseases, thromboembolism, and kidney or liver diseases (important risk factors of preeclampsia). The low frequency of preeclampsia $(2.7 \%)$ in our study is consistent with the literature data and our methodology. According to the latest FIGO report from 2019 (The International Federation of Gynecology and Obstetrics), preeclampsia affects $2 \%-5 \%$ of pregnant women [47]. In the current analysis, the number of IUGR cases $(n=13)$ and the number of preeclampsia cases $(n=15)$ was small and the results for these cases should be evaluated with caution and treated only as a pilot study.

The mechanisms of the results identified are not fully explained, but the relationships between lower microelement levels and oxidative stress intensification are taken into account. Selenium (Se), zinc $(\mathrm{Zn})$, copper $(\mathrm{Cu})$, and iron $(\mathrm{Fe})$ are involved in many biochemical processes and show antioxidant 
and anti-inflammatory properties, and their deficiency (or excess) is associated with an increase in oxidative stress and inflammation [12-15,48].

Oxidative stress and inflammation have been shown to be important in the pathogenesis of adverse pregnancy results $[3,12,13]$. Pregnancy induced hypertension is characterized by an increase de novo in blood pressure after the 20th week of pregnancy, however, evidence available in the literature suggests that adverse pregnancy outcomes and complications may be due to placental dysfunction in early pregnancy $[12,49]$. Disorders of trophoblast invasion (during placental development before the 20th week) result in the development of high-resistance placental circulation, reduction of blood flow in the placental circulation, and hypoxia, as well as an increase in levels of reactive oxygen species (ROS) and an increase in oxidative stress. It affects the immune system and apoptosis and increases inflammatory response. Adequate levels of antioxidative and/or anti-inflammatory selenoproteins (such as glutathione peroxidases (GPx), thioredoxin reductases (Th-Redx), and selenoproteins P) are needed to protect placental, fetal, and maternal tissue against oxidative stress and oxidative damage [12]. Literature data show that lower levels of Se were associated with a lower activity of these selenoproteins [12]. Increased oxidative stress and many other processes in the placenta and systemic circulation system result in the damage of the vascular endothelium and disturbance of endothelial homeostasis [12]. The activation of many markers (e.g., oxidative stress markers, inflammatory cytokines, von Willebrand factor, endothelin-1, fibronectin, etc.) and deficiency of vasodilators (as nitric oxide and prostacyclin) result in blood pressure increase [11-15,48,49].

In mechanisms of preterm birth development, the relationships between lower Se levels and oxidative stress and inflammation intensification and other factors, such as weakening of the immune protection and increased risk of infection, are taken into account $[5,50]$. Placental insufficiency is also the cause of IUGR [12].

However, it remains unexplained and poorly investigated as to what is the cause of abnormal trophoblast invasion in the first half of pregnancy. Genetic, environmental, and metabolic factors are considered, including oxidative stress and inflammation, as the primary cause [49]. A deficiency of selenium and inadequate activity of antioxidative systems in the uterus can cause disorders of the trophoblast cell function. Moreover, other activities of this element are taken into consideration. Deficiency of their antioxidant and anti-inflammatory effects in early pregnancy may be associated with the development of adverse pregnancy results [12,13].

Although the diet is a basic determinant of microelement levels in the body [51], various factors, e.g., obesity, smoking, alcohol, or older age, can change their levels in tissues, as several studies in the general population have shown $[52,53]$, and these factors have been associated with increased oxidative stress and inflammation [52,54-58]. However, the number of studies on pregnant women is limited [1,28,54]. Importantly, lifestyle indicators (such as obesity, smoking, or alcohol consumption) and lower socioeconomic factors (lower education or financial levels) increase the risk of adverse pregnancy outcomes [2].

Obesity has been associated with lower levels of Se, Fe, and $\mathrm{Zn}$ in the general population [54,55,59-61], though there are also discrepancies which is consistent with our negative relationship between maternal prepregnancy BMI and Se or Fe [62]. The statistically and positive relationships between $\mathrm{Cu}$ levels and prepregnancy BMI found in our study are also confirmed in the literature and is explained by the increase in Cu-binding ceruloplasmin (acute phase protein) [63].

Smoking is mentioned as a factor that lowers Se levels in the general population [52]. A reduction of Se levels in smokers may result from interactions, e.g., with cadmium accumulated in smokers' bodies $[13,15,64]$. Aging is associated with the lowering of Se levels [52]; however in the present study, women aged 18-45 were evaluated and statistically positive relationships between maternal age and Se levels were found. It means that other factors can also affect these correlations, e.g., diet or hormonal factors [65].

The literature confirms the increase in $\mathrm{Cu}$ concentrations along with the duration of pregnancy and it is explained by the synthesis of ceruloplasmin (it has not been fully elucidated) [66,67], but it is 
noteworthy that the gestational age range (when microelements were measured) in our study was narrow (from the 10-14th week). According to the literature, the levels of Se, $\mathrm{Zn}$, and Fe are reduced in pregnancy $[12,28,54,67,68]$.

Socioeconomic indicators, geographical location, seasonality, race and ethnic differences, as well as gender also affect the level of elements [28,52,69]. Lower socioeconomic factors may be associated with an unhealthy lifestyle, including improper diet, obesity, smoking, or noncompliance with medical recommendations, e.g., regarding vitamin supplementation in pregnancy [28]. Different diets at different times of the year can affect seasonal differences in microelement levels [69].

Geographical differences in the content of elements in soil mainly concern selenium and affect the differences in the content of this element in plants and animals, and then in people [70,71]. In developed countries, there is currently no deficiency of zinc, which may be the result of various national dietary interventions [72]. Low levels of selenium are found in some regions of the world [70,71]. In our country, the average Se concentration is $70 \mu \mathrm{g} / \mathrm{L}(50-55 \mu \mathrm{g} / \mathrm{L}$ in some regions), and in North America it is $122.4-151.8 \mu \mathrm{g} / \mathrm{L}[70,73,74]$. Recommendations for the optimal amount of Se in the diet are based on maximizing glutathione peroxidase (GPx) [70,71]. The optimal mean serum concentration of Se (according to the World Health Organization) is 39.5-194.5 $\mu \mathrm{g} / \mathrm{L}$ for healthy adults, and 70-90 $\mu \mathrm{g} / \mathrm{L}$ was considered to maximize GPx. The average demand (estimated average requirement (EAR)) was estimated at $45 \mu \mathrm{g} /$ day for people aged 19-50 years. In pregnant women, the recommended dietary allowance (RDA) increases to $60 \mu \mathrm{g} /$ day [75]. It should also be emphasized that the adverse effects of selenium on health have a " $U$ " curve, therefore supplementation should only be used in people with a known Se deficiency. Optimizing the Se level through a balanced diet seems to be a safe method [70].

In our opinion, the current study has two main implications for clinical practice. Measuring assessed microelements (especially selenium) in early pregnancy can help identify women who have been evaluated as at risk of pregnancy complications and increase care for them; measurement of microelements is simple and available. Importantly, measurement of microelements may suggest the need for changes in diet and in health-promoting behaviors (prepregnancy BMI reduction and smoking cessation). Certain lifestyle modifications should be performed as a matter of course in every pregnant woman and not only based on low levels of microelements. The obtained results deserve further research. Additionally, the possibility of including microelement measurements in early pregnancy (or maybe before pregnancy) can be considered for screening.

\section{Advantages and Limitations}

The main advantage was the evaluation of the prospectively collected group and analysis of microelements in serum samples collected at the end of the first trimester of pregnancy. The advantage of the current study was a fairly large sample size, but further studies on larger samples are advisable. An advantage was simultaneously examining the relationship between the microelements, and the features of mothers and several pregnancy results. Another advantage of this study was the use of multivariable models of statistical analyses.

The limitation of this study may be the lack of analysis of the diet composition, but the concentrations of microelements in the serum were assumed to be a reflection of the consumption of elements (in the diet and possible supplements). We could not explore other ethnic groups because they are few in our country. The exclusion of diseases with elements of inflammation and oxidative stress was good for assessing the effect of "oxidative stress" microelements on the pregnancy results, but reduced the frequency of preeclampsia (PE). The women reported their body weight before pregnancy on their own.

\section{Conclusions and Future Work}

This study shows strong relationships between lower levels of selenium in early pregnancy and development of pregnancy-induced hypertension (PIH), including isolated gestational hypertension (GH). The weaker relationships between lower levels of microelements (Se, Fe, or $\mathrm{Cu}$ ) and PIH, 
preeclampsia, preterm birth, IUGR, and gestational diabetes mellitus (GDM) were also found. At the same time, attention should be paid to lifestyle-related factors and lower socioeconomic indicators that affect microelement levels. Our results suggest the need for changes in health-promoting behaviors. Of course, healthy behavior is needed for every pregnant woman, not only to optimize the level of microelements.

The obtained results deserve further research to clarify whether there is a causal relationship and whether the role of selenium in the early prediction of PIH is possible. It is possible, that nutritional interventions in the peri-conceptual period can help in the prevention of this pregnancy complication. It would be interesting to probably reveal differences between certain research groups, such as different racial and ethnic groups, and different geographical locations.

Supplementary Materials: The following are available online at http://www.mdpi.com/2072-6643/12/4/1108/s1, Table S1: Full characteristics of microelement levels (medians and ranges) for various maternal characteristics, Table S2: The adjusted relationships between maternal characteristics and microelement levels after additional adjusting for pregnancy-induced hypertension (PIH), Table S3: Full characteristics of microelement levels (medians and ranges) for pregnancy results, Table S4: Adjusted relationships between pregnancy results and microelements in the multivariable linear regression, Table S5: Short characteristics of mothers in the control and case groups (for PIH and preterm birth).

Author Contributions: Conceptualization, M.L.; methodology, M.L.; software, M.L.; validation, B.W., S.S., J.L., and M.L.; formal analysis, M.L.; investigation, M.L.; resources, M.L.; data curation, M.L.; writing-original draft preparation, M.L.; writing-review and editing, M.L.; visualization, M.L.; supervision, B.W., S.S., J.L., and M.L.; project administration, M.L. All authors have read and agreed to the published version of the manuscript.

Funding: This research received no external funding.

Acknowledgments: The authors would like to thank the pregnant women at the University Obstetrics and Gynecology Hospital in Poznań, Poland for their participation in this study.

Conflicts of Interest: The authors declare no conflict of interest.

\section{References}

1. Wilson, R.L.; Bianco-Miotto, T.; Leemaqz, S.Y.; Grzeskowiak, L.E.; Dekker, G.A.; Roberts, C.T. Early pregnancy maternal trace mineral status and the association with adverse pregnancy outcome in a cohort of Australian women. J. Trace Elem. Med. Biol. 2018, 46, 103-109. [CrossRef] [PubMed]

2. Duhig, K.; Vandermolen, B.; Shennan, A. Recent advances in the diagnosis and management of pre-eclampsia. F1000Research 2018, 7, 242. [CrossRef] [PubMed]

3. Ryan, A.S. Inflammatory Markers in Older Women with a History of Gestational Diabetes and the Effects of Weight Loss. J. Diabetes Res. 2018, 2018, 5172091. [CrossRef] [PubMed]

4. Plows, F.J.; Stanley, L.J.; Baker, N.P.; Reynolds, M.C.; Vickers, H.M. The Pathophysiology of Gestational Diabetes Mellitus. Int. J. Mol. Sci. 2018, 19, 3342. [CrossRef]

5. Rayman, M.P.; Wijnen, H.; Vader, H.; Kooistra, L.; Pop, V. Maternal selenium status during early gestation and risk for preterm birth. CMAJ 2011, 183, 549-555. [CrossRef] [PubMed]

6. Doty, M.S.; Chen, H.-Y.; Sibai, B.M.; Chauhan, S.P. Maternal and Neonatal Morbidity Associated With Early Term Delivery of Large-for-Gestational-Age But Nonmacrosomic Neonates. Obstet. Gynecol. 2019, 133, 1160-1166. [CrossRef]

7. Ota, E.; Ganchimeg, T.; Morisaki, N.; Vogel, J.P.; Pileggi, C.; Ortiz-Panozo, E.; Souza, J.P.; Mori, R.; WHO Multi-Country Survey on Maternal and Newborn Health Research Network. Risk factors and adverse perinatal outcomes among term and preterm infants born small-for-gestational-age: Secondary analyses of the WHO Multi-Country Survey on Maternal and Newborn Health. PLoS ONE 2014, 9, e105155. [CrossRef] [PubMed]

8. Harder, T.; Roepke, K.; Diller, N.; Stechling, Y.; Dudenhausen, J.W.; Plagemann, A. Birth weight, early weight gain, and subsequent risk of type 1 diabetes: Systematic review and meta-analysis. Am. J. Epidemiol. 2009, 169, 1428-1436. [CrossRef]

9. Rugholm, S.; Baker, J.L.; Olsen, L.W.; Schack-Nielsen, L.; Bua, J.; Sørensen, T.I.A. Stability of the association between birth weight and childhood overweight during the development of the obesity epidemic. Obes. Res. 2005, 13, 2187-2194. [CrossRef] 
10. Xue, F.; Michels, K.B. Intrauterine factors and risk of breast cancer: A systematic review and meta-analysis of current evidence. Lancet Oncol. 2007, 8, 1088-1100. [CrossRef]

11. Rayman, M.P.; Searle, E.; Kelly, L.; Johnsen, S.; Bodman-Smith, K.; Bath, S.C.; Mao, J.; Redman, C.W.G. Effect of selenium on markers of risk of pre-eclampsia in UK pregnant women: A randomised, controlled pilot trial. Br. J. Nutr. 2014, 112, 99-111. [CrossRef]

12. Mistry, H.D.; Williams, P.J. The importance of antioxidant micronutrients in pregnancy. Oxid. Med. Cell. Longev. 2011, 2011, 841749. [CrossRef]

13. Rayman, M.P. Selenium and human health. Lancet Lond. Engl. 2012, 379, 1256-1268. [CrossRef]

14. Horan, M.K.; McGowan, C.A.; Gibney, E.R.; Donnelly, J.M.; McAuliffe, F.M. The association between maternal dietary micronutrient intake and neonatal anthropometry-secondary analysis from the ROLO study. Nutr. J. 2015, 14, 105. [CrossRef] [PubMed]

15. Wołonciej, M.; Milewska, E.; Roszkowska-Jakimiec, W. Trace elements as an activator of antioxidant enzymes. Postepy Hig. Med. Dosw. 2016, 70, 1483-1498. [CrossRef] [PubMed]

16. Haque, M.M.; Moghal, M.M.R.; Sarwar, M.S.; Anonna, S.N.; Akter, M.; Karmakar, P.; Ahmed, S.; Sattar, M.A.; Islam, M.S. Low serum selenium concentration is associated with preeclampsia in pregnant women from Bangladesh. J. Trace Elem. Med. Biol. 2016, 33, 21-25. [CrossRef]

17. Li, P.; Yin, J.; Zhu, Y.; Li, S.; Chen, S.; Sun, T.; Shan, Z.; Wang, J.; Shang, Q.; Li, X.; et al. Association between plasma concentration of copper and gestational diabetes mellitus. Clin. Nutr. 2019, 38, 2922-2927. [CrossRef]

18. Mishu, F.A.; Boral, N.; Ferdous, N.; Nahar, S.; Sultana, G.S.; Yesmin, M.S.; Khan, N.Z. Estimation of Serum Zinc, Copper and Magnesium Levels in Bangladeshi women with Gestational Diabetes Mellitus Attending in a Tertiary Care Hospital. Mymensingh Med. J. 2019, 28, 157-162.

19. Lewandowska, M.; Sajdak, S.; Lubiński, J. Serum Selenium Level in Early Healthy Pregnancy as a Risk Marker of Pregnancy Induced Hypertension. Nutrients 2019, 11, 1028. [CrossRef]

20. Lewandowska, M.; Sajdak, S.; Marciniak, W.; Lubiński, J. First Trimester Serum Copper or Zinc Levels, and Risk of Pregnancy-Induced Hypertension. Nutrients 2019, 11, 2479. [CrossRef]

21. Lewandowska, M.; Sajdak, S.; Lubiński, J. Can Serum Iron Concentrations in Early Healthy Pregnancy Be Risk Marker of Pregnancy-Induced Hypertension? Nutrients 2019, 11, 1086. [CrossRef] [PubMed]

22. Ghaemi, S.Z.; Forouhari, S.; Dabbaghmanesh, M.H.; Sayadi, M.; Bakhshayeshkaram, M.; Vaziri, F.; Tavana, Z. A prospective study of selenium concentration and risk of preeclampsia in pregnant Iranian women: A nested case-control study. Biol. Trace Elem. Res. 2013, 152, 174-179. [CrossRef] [PubMed]

23. Rayman, M.P.; Bode, P.; Redman, C.W.G. Low selenium status is associated with the occurrence of the pregnancy disease preeclampsia in women from the United Kingdom. Am. J. Obstet. Gynecol. 2003, 189, 1343-1349. [CrossRef]

24. Mistry, H.D.; Kurlak, L.O.; Young, S.D.; Briley, A.L.; Pipkin, F.B.; Baker, P.N.; Poston, L. Maternal selenium, copper and zinc concentrations in pregnancy associated with small-for-gestational-age infants. Matern. Child Nutr. 2014, 10, 327-334. [CrossRef] [PubMed]

25. Bogden, J.D.; Kemp, F.W.; Chen, X.; Stagnaro-Green, A.; Stein, T.P.; Scholl, T.O. Low-normal serum selenium early in human pregnancy predicts lower birth weight. Nutr. Res. 2006, 26, 497-502. [CrossRef]

26. Lewandowska, M.; Sajdak, S.; Lubiński, J. The Role of Early Pregnancy Maternal Selenium Levels on the Risk for Small-for-Gestational Age Newborns. Nutrients 2019, 11, 2298. [CrossRef]

27. Basu, A.; Yu, J.Y.; Jenkins, A.J.; Nankervis, A.J.; Hanssen, K.F.; Henriksen, T.; Lorentzen, B.; Garg, S.K.; Menard, M.K.; Hammad, S.M.; et al. Trace elements as predictors of preeclampsia in type 1 diabetic pregnancy. Nutr. Res. 2015, 35, 421-430. [CrossRef]

28. Choi, R.; Sun, J.; Yoo, H.; Kim, S.; Cho, Y.Y.; Kim, H.J.; Kim, S.W.; Chung, J.H.; Oh, S.-Y.; Lee, S.-Y. A Prospective Study of Serum Trace Elements in Healthy Korean Pregnant Women. Nutrients 2016, 8, 749. [CrossRef]

29. Zhu, Y.; Zhang, C. Prevalence of Gestational Diabetes and Risk of Progression to Type 2 Diabetes: A Global Perspective. Curr. Diabetes Rep. 2016, 16, 7. [CrossRef]

30. UNICEF; WHO. Low Birthweight: Country, Regional and Global Estimates; UNICEF: New York, NY, USA, 2004; ISBN 92-806-3832-7.

31. Surkan, P.J.; Hsieh, C.-C.; Johansson, A.L.V.; Dickman, P.W.; Cnattingius, S. Reasons for increasing trends in large for gestational age births. Obstet. Gynecol. 2004, 104, 720-726. [CrossRef] 
32. Kirkham, R.; Whitbread, C.; Connors, C.; Moore, E.; Boyle, J.A.; Richa, R.; Barzi, F.; Li, S.; Dowden, M.; Oats, J.; et al. Implementation of a diabetes in pregnancy clinical register in a complex setting: Findings from a process evaluation. PLOS ONE 2017, 12, e0179487. [CrossRef] [PubMed]

33. Lewandowska, M.; Lubiński, J. Serum Microelements in Early Pregnancy and their Risk of Large-forGestational Age Birth Weight. Nutrients 2020, 12, 866. [CrossRef] [PubMed]

34. Ugwuja, E.I.; Ejikeme, B.N.; Ugwu, N.C.; Obeka, N.C.; Akubugwo, E.I.; Obidoa, O. Comparison of Plasma Copper, Iron and Zinc Levels in Hypertensive and Non-hypertensive Pregnant Women in Abakaliki, South Eastern Nigeria. Pak. J. Nutr. 2010, 9, 1136-1140. [CrossRef]

35. Tande, D.L.; Ralph, J.L.; Johnson, L.K.; Scheett, A.J.; Hoverson, B.S.; Anderson, C.M. First trimester dietary intake, biochemical measures, and subsequent gestational hypertension among nulliparous women. J. Midwifery Womens Health 2013, 58, 423-430. [CrossRef]

36. Irwinda, R.; Wibowo, N.; Putri, A.S. The Concentration of Micronutrients and Heavy Metals in Maternal Serum, Placenta, and Cord Blood: A Cross-Sectional Study in Preterm Birth. J. Pregnancy 2019, 2019, 5062365. [CrossRef]

37. Yıldirım, K. Transcriptomic and hormonal control of boron uptake, accumulation and toxicity tolerance in poplar. Environ. Exp. Bot. 2017, 141,60-73. [CrossRef]

38. Zhuang, T.; Han, H.; Yang, Z. Iron, Oxidative Stress and Gestational Diabetes. Nutrients 2014, 6, 3968-3980. [CrossRef]

39. Kong, F.-J.; Ma, L.-L.; Chen, S.-P.; Li, G.; Zhou, J.-Q. Serum selenium level and gestational diabetes mellitus: A systematic review and meta-analysis. Nutr. J. 2016, 15, 94. [CrossRef]

40. Mao, J.; Bath, S.C.; Vanderlelie, J.J.; Perkins, A.V.; Redman, C.W.G.; Rayman, M.P. No effect of modest selenium supplementation on insulin resistance in UK pregnant women, as assessed by plasma adiponectin concentration. Br. J. Nutr. 2016, 115, 32-38. [CrossRef]

41. Hamdan, H.Z.; Elbashir, L.M.; Hamdan, S.Z.; Elhassan, E.M.; Adam, I. Zinc and selenium levels in women with gestational diabetes mellitus at Medani Hospital, Sudan. J. Obstet. Gynaecol. 2014, 34, 567-570. [CrossRef]

42. Keats, E.C.; Haider, B.A.; Tam, E.; Bhutta, Z.A. Multiple-micronutrient supplementation for women during pregnancy. Cochrane Database Syst. Rev. 2019, 3, CD004905. [CrossRef] [PubMed]

43. Radoń-Pokracka, M.; Adrianowicz, B.; Płonka, M.; Danił, P.; Nowak, M.; Huras, H. Evaluation of Pregnancy Outcomes at Advanced Maternal Age. Open Access Maced. J. Med. Sci. 2019, 7, 1951-1956. [CrossRef] [PubMed]

44. Kajdy, A.; Modzelewski, J.; Jakubiak, M.; Pokropek, A.; Rabijewski, M. Effect of antenatal detection of small-for-gestational-age newborns in a risk stratified retrospective cohort. PLoS ONE 2019, 14, e0224553. [CrossRef] [PubMed]

45. LifeCycle Project-Maternal Obesity and Childhood Outcomes Study Group; Voerman, E.; Santos, S.; Inskip, H.; Amiano, P.; Barros, H.; Charles, M.-A.; Chatzi, L.; Chrousos, G.P.; Corpeleijn, E.; et al. Association of Gestational Weight Gain With Adverse Maternal and Infant Outcomes. JAMA 2019, 321, 1702-1715. [CrossRef]

46. Wierzba, W.; Śliwczyński, A.; Karnafel, W.; Bojar, I.; Pinkas, J. Gestational diabetes mellitus/hyperglycaemia during pregnancy in Poland in the years 2010-2012 based on the data from the National Health Fund. Ginekol. Pol. 2017, 88, 244-248. [CrossRef]

47. Poon, L.C.; Shennan, A.; Hyett, J.A.; Kapur, A.; Hadar, E.; Divakar, H.; McAuliffe, F.; da Silva Costa, F.; von Dadelszen, P.; McIntyre, H.D.; et al. The International Federation of Gynecology and Obstetrics (FIGO) initiative on pre-eclampsia: A pragmatic guide for first-trimester screening and prevention. Int. J. Gynaecol. Obstet. 2019, 145, 1-33. [CrossRef]

48. Mannaerts, D.; Faes, E.; Cos, P.; Briedé, J.J.; Gyselaers, W.; Cornette, J.; Gorbanev, Y.; Bogaerts, A.; Spaanderman, M.; Van Craenenbroeck, E.; et al. Oxidative stress in healthy pregnancy and preeclampsia is linked to chronic inflammation, iron status and vascular function. PLoS ONE 2018, 13, e202919. [CrossRef]

49. Mendes, S.; Timóteo-Ferreira, F.; Almeida, H.; Silva, E. New Insights into the Process of Placentation and the Role of Oxidative Uterine Microenvironment. Oxid. Med. Cell. Longev. 2019, 2019, 9174521. [CrossRef]

50. Logiodice, F.; Lombardelli, L.; Kullolli, O.; Haller, H.; Maggi, E.; Rukavina, D.; Piccinni, M.-P. Decidual Interleukin-22-Producing CD4+ T Cells (Th17/Th0/IL-22+ and Th17/Th2/IL-22+, Th2/IL-22+, Th0/IL-22+), Which Also Produce IL-4, Are Involved in the Success of Pregnancy. Int. J. Mol. Sci. 2019, 20, 428. [CrossRef] 
51. Lu, C.-W.; Chang, H.-H.; Yang, K.-C.; Chiang, C.-H.; Yao, C.-A.; Huang, K.-C. Gender Differences with Dose $^{-}$Response Relationship between Serum Selenium Levels and Metabolic Syndrome-A Case-Control Study. Nutrients 2019, 11, 477. [CrossRef]

52. Park, K.; Rimm, E.; Siscovick, D.; Spiegelman, D.; Morris, J.S.; Mozaffarian, D. Demographic and lifestyle factors and selenium levels in men and women in the U.S. Nutr. Res. Pract. 2011, 5, 357-364. [CrossRef] [PubMed]

53. Barden, A.; Zilkens, R.R.; Croft, K.; Mori, T.; Burke, V.; Beilin, L.J.; Puddey, I.B. A reduction in alcohol consumption is associated with reduced plasma F2-isoprostanes and urinary 20-HETE excretion in men. Free Radic. Biol. Med. 2007, 42, 1730-1735. [CrossRef] [PubMed]

54. Mao, J.; Vanderlelie, J.J.; Perkins, A.V.; Redman, C.W.G.; Ahmadi, K.R.; Rayman, M.P. Genetic polymorphisms that affect selenium status and response to selenium supplementation in United Kingdom pregnant women. Am. J. Clin. Nutr. 2016, 103, 100-106. [CrossRef] [PubMed]

55. Hosseini, B.; Saedisomeolia, A.; Allman-Farinelli, M. Association Between Antioxidant Intake/Status and Obesity: A Systematic Review of Observational Studies. Biol. Trace Elem. Res. 2017, 175, 287-297. [CrossRef] [PubMed]

56. Olechnowicz, J.; Tinkov, A.; Skalny, A.; Suliburska, J. Zinc status is associated with inflammation, oxidative stress, lipid, and glucose metabolism. J. Physiol. Sci. JPS 2018, 68, 19-31. [CrossRef] [PubMed]

57. Pretorius, E.; Akeredolu, O.O.; Soma, P.; Kell, D.B. Major involvement of bacterial components in rheumatoid arthritis and its accompanying oxidative stress, systemic inflammation and hypercoagulability. Exp. Biol. Med. Maywood 2017, 242, 355-373. [CrossRef]

58. Chełchowska, M.; Ambroszkiewicz, J.; Gajewska, J.; Mazur, J.; Lewandowski, L.; Reśko-Zachara, M.; Maciejewski, T.M. Influence of Active Exposure to Tobacco Smoke on Nitric Oxide Status of Pregnant Women. Int. J. Environ. Res. Public Health 2018, 15, 2719. [CrossRef]

59. Fan, Y.; Zhang, C.; Bu, J. Relationship between Selected Serum Metallic Elements and Obesity in Children and Adolescent in the U.S. Nutrients 2017, 9, 104. [CrossRef]

60. Zhao, L.; Zhang, X.; Shen, Y.; Fang, X.; Wang, Y.; Wang, F. Obesity and iron deficiency: A quantitative meta-analysis. Obes. Rev. 2015, 16, 1081-1093. [CrossRef]

61. Fukunaka, A.; Fujitani, Y. Role of Zinc Homeostasis in the Pathogenesis of Diabetes and Obesity. Int. J. Mol. Sci. 2018, 19, 476. [CrossRef]

62. Jaksic, M.; Martinovic, M.; Gligorovic-Barhanovic, N.; Vujacic, A.; Djurovic, D.; Nedovic-Vukovic, M. Association between inflammation, oxidative stress, vitamin D, copper and zinc with pre-obesity and obesity in school children from the city of Podgorica, Montenegro. J. Pediatr. Endocrinol. Metab. 2019, 32, 951-957. [CrossRef] [PubMed]

63. Gaetke, L.M.; Chow-Johnson,H.S.; Chow, C.K. Copper: Toxicological relevance and mechanisms. Arch. Toxicol. 2014, 88, 1929-1938. [CrossRef]

64. Sun, H.; Chen, W.; Wang, D.; Jin, Y.; Chen, X.; Xu, Y. The effects of prenatal exposure to low-level cadmium, lead and selenium on birth outcomes. Chemosphere 2014, 108, 33-39. [CrossRef] [PubMed]

65. Stråvik, M.; Jonsson, K.; Hartvigsson, O.; Sandin, A.; Wold, A.E.; Sandberg, A.-S.; Barman, M. Food and Nutrient Intake during Pregnancy in Relation to Maternal Characteristics: Results from the NICE Birth Cohort in Northern Sweden. Nutrients 2019, 11, 1680. [CrossRef]

66. Al-Jameil, N.; Tabassum, H.; Al-Mayouf, H.; Aljohar, H.I.; Alenzi, N.D.; Hijazy, S.M.; Khan, F.A. Analysis of serum trace elements-copper, manganese and zinc in preeclamptic pregnant women by inductively coupled plasma optical emission spectrometry: A prospective case controlled study in Riyadh, Saudi Arabia. Int. J. Clin. Exp. Pathol. 2014, 7, 1900-1910. [PubMed]

67. Tabrizi, F.M.; Pakdel, F.G. Serum Level of Some Minerals during Three Trimesters of Pregnancy in Iranian Women and Their Newborns: A Longitudinal Study. Indian J. Clin. Biochem. 2014, 29, 174-180. [CrossRef]

68. Shen, P.-J.; Ging, B.; Xu, F.-Y.; Luo, Y. Four trace elements in pregnant women and their relationships with adverse pregnancy outcomes. Eur. Rev. Med. Pharmacol. Sci. 2015, 19, 4690-4697. [PubMed]

69. Liang, C.-M.; Wu, X.-Y.; Huang, K.; Yan, S.-Q.; Li, Z.-J.; Xia, X.; Pan, W.-J.; Sheng, J.; Tao, Y.-R.; Xiang, H.-Y.; et al. Trace element profiles in pregnant women's sera and umbilical cord sera and influencing factors: Repeated measurements. Chemosphere 2019, 218, 869-878. [CrossRef]

70. Kieliszek, M.; Błażejak, S. Current Knowledge on the Importance of Selenium in Food for Living Organisms: A Review. Molecules 2016, 21, 609. [CrossRef] 
71. Ibrahim, S.A.Z.; Kerkadi, A.; Agouni, A. Selenium and Health: An Update on the Situation in the Middle East and North Africa. Nutrients 2019, 11, 1457. [CrossRef]

72. Grieger, J.A.; Grzeskowiak, L.E.; Wilson, R.L.; Bianco-Miotto, T.; Leemaqz, S.Y.; Jankovic-Karasoulos, T.; Perkins, A.V.; Norman, R.J.; Dekker, G.A.; Roberts, C.T. Maternal Selenium, Copper and Zinc Concentrations in Early Pregnancy, and the Association with Fertility. Nutrients 2019, 11, 1609. [CrossRef] [PubMed]

73. Wilk, A.; Szypulska-Koziarska, D.; Marchelek-Myśliwiec, M.; Głazek, W.; Wiszniewska, B. Serum Selenium, Iron, Zinc, and Copper Concentrations in Renal Transplant Recipients Treated with Mycophenolate Mofetil. Biol. Trace Elem. Res. 2020. [CrossRef] [PubMed]

74. Wilk, A.; Wiszniewska, B. Arsenic and Selenium Profile in Erythrocytes of Renal Transplant Recipients. Biol. Trace Elem. Res. 2019. [CrossRef]

75. Rocourt, C.R.B.; Cheng, W.-H. Selenium supranutrition: Are the potential benefits of chemoprevention outweighed by the promotion of diabetes and insulin resistance? Nutrients 2013, 5, 1349-1365. [CrossRef] [PubMed]

(C) 2020 by the authors. Licensee MDPI, Basel, Switzerland. This article is an open access article distributed under the terms and conditions of the Creative Commons Attribution (CC BY) license (http://creativecommons.org/licenses/by/4.0/). 